\title{
Threshold responses of juniper tree growth and regeneration to climate warming and drought stress at alpine treeline
}

\author{
Xiaoming Lu ${ }^{1} \cdot$ J. Julio Camarero ${ }^{2} \cdot$ Eryuan Liang $^{1}$ \\ Received: 14 April 2021 / Accepted: 15 April 2021 / Published online: 29 April 2021 \\ (c) The Author(s), under exclusive licence to Springer-Verlag GmbH Germany, part of Springer Nature 2021
}

Alpine treelines are suitable monitors of ecosystem responses to climate warming (Körner 1998). In general, the alpine treeline position is considered to be largely controlled by temperature (Harsch et al. 2009). Since high-elevation areas have shown a rapid warming rate (Yao et al. 2019), a growth enhancement and upward treeline shifts are expected. However, moisture could mediate the sensitivity of treeline shifts to climate warming in the twenty-first century (Lu et al. 2021) and treeline responses to temperature could be lower than predicted by warming trends (Camarero et al. 2021). Increasing drought stress due to climate warming has caused widespread forest dieback and growth decline (Babst et al. 2019; Brodribb et al. 2020). Global warming may further have profound implications on alpine treelines through a reduction of soil moisture causing a decrease in growth and an increase in mortality rates. For example, tree growth could become less dependent on temperature changes at warmer and drier alpine treelines (Liang et al. 2019; Elliott et al. 2021; Camarero et al. 2021). Such threshold responses are keys for effectively understanding and forecasting alpine treeline dynamics; however, few studies have captured the tipping points or change thresholds in the relationships between temperature and tree growth and regeneration at alpine treelines (Huang et al. 2019a; Du et al. 2020).

Zhang et al. (2021, this issue) focused on a threshold response of juniper tree (Juniperus przewalskii Kom.) growth and recruitment to drought stress related to climatic warming at alpine treelines located in the eastern Qilian Mountains, northeastern Tibetan Plateau, a region characterized by continental and dry conditions. They found

Eryuan Liang

liangey@itpcas.ac.cn

1 State Key Laboratory of Tibetan Plateau Earth System Science (LATPES), Institute of Tibetan Plateau Research, Chinese Academy of Sciences, Beijing 100101, China

2 Instituto Pirenaico de Ecología (IPE-CSIC), Avenida Montañana 1005, 50059 Zaragoza, Spain that juniper recruitment increased until the 1940s, and then rapidly declined after the 1970s. Mortality of saplings increased during the period 1959-1999 and reached a peak in 2000-2004 as climate warmed and dried. In addition, the radial growth of adult trees became less responsive to climate warming since 1988. These findings suggest agedependent vulnerability to climate stress in the alpine treeline and illustrate the performance of tree population dynamics after passing climatic thresholds, providing fundamental knowledge for modeling alpine treeline dynamics.

Increasing mortality risk of tree regeneration may threaten the stability of high-elevation forests and treelines in the study area. First, current drought stress significantly limits juniper and Qinghai spruce (Picea crassifolia) growth in this area (Shao et al. 2010; Yang et al. 2014; Zhang et al. 2015). This is translated into higher frequency of missing rings as climate warming induces water shortage at the alpine treeline (Liang et al. 2016). Second, field survey data indicate increasing tree mortality and growth suppression since the 1940s and 1950s, simultaneously with the rapid temperature increase (Liang et al. 2016; Wang et al. 2018). Zhang et al. (2021) illustrated a higher vulnerability of saplings than adult trees in response to drought stress at the alpine treeline. As climate warming proceeds, drought stress may exceed the physiological threshold of sapling survival recruited at the treeline during wetter periods (Fig. 1). It is likely that old trees were more capable of adapting to drying, because their more developed root systems allowed them to access to deeper soil moisture pools. This idea might be tested by analyzing $\mathrm{H}$ and $\mathrm{O}$ isotopes in soil and xylem water at treeline (Huang et al. 2019b; Wang et al. 2020). As a result, the higher resilience of old trees may allow them to be less coupled with changes in temperature (Camarero et al. 2021). Forest dieback and growth decline at treeline are concerning phenomena since mountain forest ecosystems provide substantial ecological and climatological benefits to society. Given a rapid climate warming in the future, 


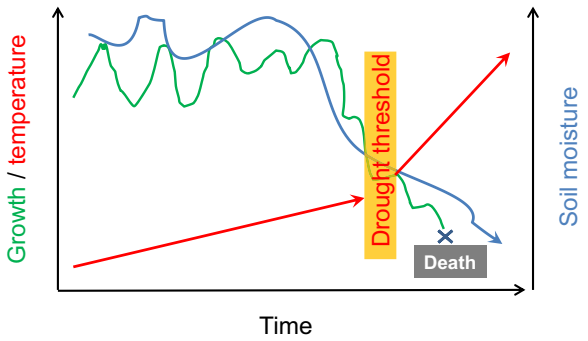

Fig. 1 Theoretical process of how increasing drought stress associated with climate warming may lead to increasing mortality of saplings and trees at the alpine treeline once a drought lethal threshold is surpassed. The green line shows the ring-width series of a dying tree

the low recruitment and high mortality of saplings may lead juniper treelines to local dieback and retraction on the northeastern Tibetan Plateau.

There is increasing interest in the development of tools to predict forest dieback and tree mortality from drought stress (Trugman et al. 2021). A better scientific understanding of the biology needed to develop those tools would allow identifying threshold responses of alpine treelines to climate warming and drought stress as already pointed out on the Tibetan Plateau (Lu et al. 2019). Dendroecology has offered a clear insight into long-term drought effects on growth and recruitment processes (e.g., Camarero et al. 2015; Xu et al. 2017). Tree-ring studies may also be applied to reconstruct and identify climate thresholds affecting treeline dynamics at inter- and intra-annual scales. For instance, it was found that both temperature and precipitation requirements should be met to start spring cambial cell division at dry juniper treelines on the northeastern Tibetan Plateau (Ren et al. 2018). A mismatch between the temperature and soil moisture thresholds for the onset of xylogenesis may increase treeline vulnerability in semi-arid areas under forecasted warmer and drier conditions. Thus, long-term monitoring of xylogenesis may provide a better understanding of the threshold responses of treelines to climatic change. Therefore, an integration of retrospective (dendroecology) and onsite monitoring methods (e.g., xylogenesis, plot surveys) at different temporal scales may further improve our understandings on the tipping points of tree growth and regeneration at the alpine treeline in response to climate. Last but not least, the research by Zhang et al. (2021) also called for a pressing need for sustainable forest management in cold, semi-arid biomes such as the northeastern Tibetan Plateau.

Author contribution statement XL wrote the first draft, JJC and EL contributed to revision and interpretation.
Acknowledgements EL was supported by the National Natural Science Foundations of China (42030508).

Author contributions XL wrote the first draft, JJC and EL contributed to revision and interpretation.

\section{Declarations}

Conflict of interest The authors declare no competing interests.

\section{References}

Babst F, Bouriaud O, Poulter B, Trouet V, Girardin MP, Frank DC (2019) Twentieth century redistribution in climatic drivers of global tree growth. Sci Adv 5:eaat4313

Brodribb TJ, Powers J, Cochard H, Choat B (2020) Hanging by a thread? Forests and drought. Science 368:261-266

Camarero JJ, Gazol A, Sangüesa-Barreda G, Oliva J, Vicente-Serrano SM (2015) To die or not to die: early warnings of tree dieback in response to a severe drought. J Ecol 103:44-57

Camarero JJ et al (2021) Global fading of the temperature-growth coupling at alpine and polar treelines. Glob Change Biol 27:1879-1889

Du Q, Rossi S, Lu X, Wang Y, Zhu H, Liang E, Camarero JJ (2020) Negative growth responses to temperature of sympatric species converge under warming conditions in the southeastern Tibetan Plateau. Trees 34:395-404

Elliott GP, Bailey SN, Cardinal SJ (2021) Hotter drought as a disturbance at upper treeline in the southern Rocky Mountains. Ann Am Assoc Geogr 111:756-770

Harsch MA, Hulme PE, McGlone MS, Duncan RP (2009) Are treelines advancing? A global meta-analysis of treeline response to climate warming. Ecol Lett 12:1040-1049

Huang $\mathrm{M}$ et al (2019a) Air temperature optima of vegetation productivity across global biomes. Nat Ecol Evol 3:772-779

Huang R et al (2019b) Temperature signals in tree-ring oxygen isotope series from the northern slope of the Himalaya. Earth Planet Sci Lett 506:455-465

Körner C (1998) A re-assessment of high elevation treeline positions and their explanation. Oecologia 115:445-459

Liang E, Leuschner C, Dulamsuren C, Wagner B, Hauck M (2016) Global warming-related tree growth decline and mortality on the north-eastern Tibetan plateau. Clim Change 134:163-176

Liang E, Dawadi B, Pederson N, Piao S, Zhu H, Sigdel SR, Chen D (2019) Strong link between large tropical volcanic eruptions and severe droughts prior to monsoon in the central Himalayas revealed by tree-ring records. Sci Bull 64:1018-1023

Lu X, Liang E, Wang Y, Babst F, Leavitt SW, Camarero JJ (2019) Past the climate optimum: Recruitment is declining at the world's highest juniper shrublines on the Tibetan Plateau. Ecology 100:e02557

Lu X, Liang E, Wang Y, Babst F, Camarero JJ (2021) Mountain treelines climb slowly despite rapid climate warming. Glob Ecol Biogeogr 30:305-315

Ren P, Rossi S, Camarero JJ, Ellison AM, Liang E, Peñuelas J (2018) Critical temperature and precipitation thresholds for the onset of xylogenesis of Juniperus przewalskii in a semi-arid area of the north-eastern Tibetan Plateau. Ann Bot 121:617-624

Shao X, Xu Y, Yin Z, Liang E, Zhu H, Wang S (2010) Climatic implications of a 3585-year tree-ring width chronology from the northeastern Qinghai-Tibetan Plateau. Quat Sci Rev 29:2111-2122

Trugman AT, Anderegg LDL, Anderegg WRL, Das AJ, Stephenson NL (2021) Why is tree drought mortality so hard to predict? Trends Ecol Evol. https://doi.org/10.1016/j.tree.2021.02.001 
Wang B, Chen T, Xu G, Wu M, Zhang G, Li C, Wu G (2018) Anthropogenic-management could mitigate declines in growth and survival of Qinghai spruce (Picea crassifolia) in the east Qilian Mountains, northeast Tibetan Plateau. Agr For Meteorol 250-251:118-126

Wang Y, Liu X, Anhäuser T, Lu Q, Zeng X, Zhang Q, Wang K, Zhang L, Zhang Y, Keppler F (2020) Temperature signal recorded in $\delta^{2} \mathrm{H}$ and $\delta^{13} \mathrm{C}$ values of wood lignin methoxyl groups from a permafrost forest in northeastern China. Sci Total Environ 727:138558

Xu C, Liu H, Anenkhonov OA, Korolyuk AY, Sandanov DV, Balsanova LD, Naidanov BB, Wu X (2017) Long-term forest resilience to climate change indicated by mortality, regeneration, and growth in semiarid southern Siberia. Glob Change Biol 23:2370-2382

Yang B, Qin C, Wang J, He M, Melvin TM, Osborn TJ, Briffa KR (2014) A 3500-year tree-ring record of annual precipitation on the northeastern Tibetan Plateau. PNAS 111:2903-2908

Yao T et al (2019) Recent Third Pole's rapid warming accompanies cryospheric melt and water cycle intensification and interactions between monsoon and environment: multidisciplinary approach with observations, modeling, and analysis. B Am Meteorol Soc 100:423-444

Zhang Q, Evans MN, Lyu L (2015) Moisture dipole over the Tibetan Plateau during the past five and a half centuries. Nat Commun 6:8062

Zhang F, Chen Q, Gou X, Du M, Wang F, Zhang J (2021) Climatic control on the growth and regeneration of Juniperus przewalskii at alpine treeline in the eastern Qilian Mountains, northwest China. Trees. https://doi.org/10.1007/s00468-021-02123-w

Publisher's Note Springer Nature remains neutral with regard to jurisdictional claims in published maps and institutional affiliations. 